PREDICTABLE STIMULUS AND TIMING IN DUAL-TASKING

\title{
Appendix
}

Table A1

Mean reaction times (RTs) and standard deviation of the mean in practice blocks in Experiment 1.

\begin{tabular}{lllllll}
\hline Block & 1Practice & \multicolumn{5}{c}{ 2Practice } \\
& $M$ & $S D$ & $M$ & $S D$ & $M$ & $S D$ \\
& $(\mathrm{~ms})$ & $(\mathrm{ms})$ & $(\mathrm{ms})$ & $(\mathrm{ms})$ & $(\mathrm{ms})$ & $(\mathrm{ms})$ \\
\hline \multirow{7}{*}{ RTs } & 760 & 128 & 761 & 192 & 751 & 186 \\
\hline \multirow{7}{*}{ Two-choice task } \\
RTs & 723 & 259 & 684 & 245 & 640 & 228 \\
\hline
\end{tabular}

Table A2

Mean reaction times $(R T s)$ and standard deviation of the mean in three testing blocks in Experiment 1.

\begin{tabular}{|c|c|c|c|c|c|c|}
\hline \multirow[t]{2}{*}{ Block } & \multicolumn{2}{|c|}{$\begin{array}{l}\text { Ran SOA } \\
\text { Ran Stim }\end{array}$} & \multicolumn{2}{|c|}{$\begin{array}{l}\text { Ran SOA } \\
\text { Seq Stim }\end{array}$} & \multicolumn{2}{|c|}{$\begin{array}{l}\text { Seq SOA } \\
\text { Ran Stim }\end{array}$} \\
\hline & $\begin{array}{l}M \\
(\mathrm{~ms})\end{array}$ & $\begin{array}{l}S D \\
(\mathrm{~ms})\end{array}$ & $\begin{array}{l}M \\
(\mathrm{~ms})\end{array}$ & $\begin{array}{l}S D \\
(\mathrm{~ms})\end{array}$ & $\begin{array}{l}M \\
(\mathrm{~ms})\end{array}$ & $\begin{array}{l}S D \\
(\mathrm{~ms})\end{array}$ \\
\hline \multicolumn{7}{|c|}{ Two-choice task } \\
\hline SOA $200 \mathrm{~ms}$ & 674 & 200 & 644 & 165 & 673 & 190 \\
\hline SOA $500 \mathrm{~ms}$ & 823 & 178 & 816 & 130 & 812 & 165 \\
\hline Average & 749 & 184 & 729 & 184 & 741 & 170 \\
\hline \multicolumn{7}{|c|}{ Four-choice task (SRTT) } \\
\hline SOA $200 \mathrm{~ms}$ & 723 & 208 & 670 & 195 & 719 & 209 \\
\hline SOA $500 \mathrm{~ms}$ & 630 & 159 & 544 & 180 & 617 & 148 \\
\hline Average & 676 & 182 & 607 & 185 & 668 & 176 \\
\hline
\end{tabular}

Table A3

Mean reaction times $(R T s)$ and standard deviation of the mean in practice blocks in Experiment 2.

\begin{tabular}{lllllll}
\hline Block & 1Practice & & 2Practice & \multicolumn{2}{l}{ 3Practice } \\
& & & & & \\
\hline$M$ & $S D$ & $M$ & $S D$ & $M$ & $S D$ \\
\hline
\end{tabular}


PREDICTABLE STIMULUS AND TIMING IN DUAL-TASKING

(ms)

$(\mathrm{ms}) \quad(\mathrm{ms}) \quad(\mathrm{ms}) \quad(\mathrm{ms}) \quad(\mathrm{ms})$

Two-choice task

$\begin{array}{lllllll}\text { RTs } & 815 & 149 & 807 & 174 & 789 & 162\end{array}$

\section{Four-choice task (SRTT)}

$\begin{array}{lllllll}\text { RTs } & 780 & 229 & 733 & 229 & 697 & 234\end{array}$

Table A4

Mean reaction times (RTs) and standard deviation of the mean in four testing blocks with SOA $200 \mathrm{~ms}$ and SOA $500 \mathrm{~ms}$ in Experiment 2.

\begin{tabular}{lllllllll}
\hline Block & $\begin{array}{l}\text { Ran_SOA } \\
\text { Ran_Stim }\end{array}$ & \multicolumn{3}{c}{$\begin{array}{l}\text { Ran_SOA } \\
\text { Seq_Stim }\end{array}$} & \multicolumn{2}{c}{$\begin{array}{l}\text { Seq_SOA } \\
\text { Ran_Stim }\end{array}$} & \multicolumn{3}{c}{$\begin{array}{l}\text { Seq_SOA } \\
\text { Seq_Stim }\end{array}$} \\
& $M$ & $S D$ & $M$ & $S D$ & $M$ & $S D$ & $M$ & $S D$ \\
& $(\mathrm{~ms})$ & $(\mathrm{ms})$ & $(\mathrm{ms})$ & $(\mathrm{ms})$ & $(\mathrm{ms})$ & $(\mathrm{ms})$ & $(\mathrm{ms})$ & $(\mathrm{ms})$ \\
\hline & & \multicolumn{7}{c}{ Two-choice task } \\
SOA 200 ms & 720 & 198 & 695 & 177 & 698 & 199 & 681 & 170 \\
SOA 500 ms & 856 & 160 & 860 & 133 & 852 & 145 & 846 & 140 \\
\hline Average & 790 & 173 & 777 & 152 & 774 & 168 & 762 & 147 \\
\hline & & & Four-choice task (SRTT) & & & \\
SOA 200 ms & 772 & 248 & 723 & 233 & 753 & 226 & 713 & 238 \\
SOA 500 ms & 650 & 204 & 594 & 199 & 635 & 168 & 573 & 216 \\
\hline Average & 710 & 225 & 657 & 212 & 694 & 195 & 644 & 225 \\
\hline
\end{tabular}

\section{Analysis of response order}

Response order in Experiment 1. Table A5 displays the effect of SOA on order of responding in the two tasks. The proportion of responding to SRTT first was subjected to a two-factorial ANOVA with block type (random SOA random stimulus vs. random SOA sequence stimulus vs. sequence SOA random stimulus) and SOA (200 ms vs. $500 \mathrm{~ms})$ as factors. Participants were more likely to respond to SRTT first at long SOA $(M=5.6 \%, S D=9.8 \%)$ than at short SOA $(M=3 \%, S D=10 \%)$, demonstrating a main effect of SOA, $F(1,27)=9.68, p=.004, \eta_{p}{ }^{2}=.26$. There was no main effect of block type, $F<1$. but an interaction of block type $\times \operatorname{SOA}, F(2,54)=7.97, p=.001, \eta_{p}{ }^{2}=.23$, suggested that participants responded to the four-choice task first more frequently when there was a fixed repeating position sequence in long SOA than in short SOA (8.5\% vs. $2.5 \%)$.

Table A5

Proportion of trials in which the response to the SRTT (Task2) was given prior to the two-choice task (Task 1) response in the testing blocks of Experiment 1. 
PREDICTABLE STIMULUS AND TIMING IN DUAL-TASKING

\begin{tabular}{lllllll}
\hline & $\begin{array}{l}\text { Ran SOA } \\
\text { Ran Stim }\end{array}$ & & $\begin{array}{l}\text { Ran SOA } \\
\text { Seq Stim }\end{array}$ & \multicolumn{3}{l}{$\begin{array}{l}\text { Seq SOA } \\
\text { Ran Stim }\end{array}$} \\
\hline & $M$ & $S D$ & $M$ & $S D$ & $M$ & $S D$ \\
\hline SOA 200 ms & $2.4 \%$ & $7.5 \%$ & $2.5 \%$ & $7.3 \%$ & $4.2 \%$ & $1.4 \%$ \\
SOA 500 ms & $2.9 \%$ & $3.6 \%$ & $8.5 \%$ & $8.4 \%$ & $5.3 \%$ & $1.4 \%$ \\
\hline Average & $2.7 \%$ & $5.8 \%$ & $5.5 \%$ & $8.4 \%$ & $4.7 \%$ & $1.4 \%$ \\
\hline
\end{tabular}

Response order in Experiment 2. The proportion of trials in which the SRTT response was given first (see Table A6) was submitted to a three-factorial ANOVA with SOA (200 ms vs. $500 \mathrm{~ms}$ ), timing sequence (random vs. sequence), and stimulus sequence (random vs. sequence). There was a main effect of SOA, $F(1,29)=16.81, p<.001, \eta_{p}{ }^{2}=.37$, due to a higher proportion of SOA $500 \mathrm{~ms}$ trials $(M=9.9 \%, S D=18.6 \%)$ in which the SRTT response came first compared to SOA $200 \mathrm{~ms}(M=$ $5.7 \%, S D=18.3 \%)$. There was no main effect of stimulus sequence, $F(1,29)=2.01, p=.17, \eta_{p}{ }^{2}=.07$, but a replicated interaction effect of stimulus sequence $\times \operatorname{SOA}, F(1,29)=6.12, p=.02, \eta_{p}{ }^{2}=.17$, suggested that effects of sequence stimulus blocks were stronger in long SOA than in short SOA $(11.7 \%$ vs. $8.1 \%)$. No other effects were significant: timing sequence, $F<1$, timing sequence $\times$ stimulus sequence, $F<1$, timing sequence $\times \operatorname{SOA}, F(1,29)=3.02, p=.09, \eta_{p}{ }^{2}=.09$, timing sequence $\times$ stimulus sequence $\times$ SOA, $F(1,29)=3.02, p=.09, \eta_{p}{ }^{2}=.09$.

Table A6

Proportion of trials in which the response to the four-choice task (the SRTT) was given prior to the two-choice task response for the testing blocks of Experiment 2.

\begin{tabular}{lllllllll}
\hline & $\begin{array}{l}\text { Ran SOA } \\
\text { Ran Stim }\end{array}$ & & \multicolumn{2}{l}{$\begin{array}{l}\text { Ran SOA } \\
\text { Seq Stim }\end{array}$} & $\begin{array}{l}\text { Seq SOA } \\
\text { Ran Stim }\end{array}$ & \multicolumn{2}{l}{$\begin{array}{l}\text { Seq SOA } \\
\text { Seq Stim }\end{array}$} \\
\hline & $M$ & $S D$ & $M$ & $S D$ & $M$ & $S D$ & $M$ & $S D$ \\
\hline SOA 200 ms & $6.3 \%$ & $18.1 \%$ & $6.7 \%$ & $20.8 \%$ & $5.4 \%$ & $19.1 \%$ & $4.6 \%$ & $15.9 \%$ \\
SOA 500 ms & $8.0 \%$ & $16.8 \%$ & $11.6 \%$ & $21.4 \%$ & $8.2 \%$ & $19.1 \%$ & $11.7 \%$ & $17.5 \%$ \\
\hline Average & $7.1 \%$ & $17.3 \%$ & $9.2 \%$ & $21.1 \%$ & $6.8 \%$ & $19.0 \%$ & $8.1 \%$ & $17.0 \%$ \\
\hline
\end{tabular}

\section{Repeating analyses while excluding trials in which the SRTT response was provided first}

Results were in line with the analyses not excluding reversal trials.

Experiment 1: Test of the impact of SOA. In contrast to the PRP effect, RTs for the two-choice task (presented first in the experiment) at SOA $200 \mathrm{~ms}(M=659 \mathrm{~ms}, S D=174 \mathrm{~ms})$ were significantly shorter than at SOA $500 \mathrm{~ms}(M=793 \mathrm{~ms}, S D=145 \mathrm{~ms}), t(27)=-8.51, p<.001, d_{z}=1.61$.

Consistently with the PRP effect, RTs for the SRTT (presented second) at SOA $500 \mathrm{~ms}(M=605 \mathrm{~ms}$, $S D=150 \mathrm{~ms})$ were significantly shorter than at SOA $200 \mathrm{~ms}(M=704 \mathrm{~ms}, S D=198 \mathrm{~ms}), t(27)=$ $7.31, p<.001, d_{z}=1.38$. 
PREDICTABLE STIMULUS AND TIMING IN DUAL-TASKING

Experiment 2: Test of the impact of SOA. In contrast to the PRP effect, RTs for two-choice task (presented first in the experiment) at SOA $200 \mathrm{~ms}(M=696 \mathrm{~ms}, S D=178 \mathrm{~ms})$ were significantly lower than at SOA $500 \mathrm{~ms}(M=827 \mathrm{~ms}, S D=151 \mathrm{~ms}), t(29)=-10.67, p<.001, d_{z}=1.92$. In agreement with the PRP effect, RTs for SRT-responses (presented second) at SOA $500 \mathrm{~ms}(M=621$ $\mathrm{ms}, S D=186 \mathrm{~ms})$ were significantly shorter than at SOA $200 \mathrm{~ms}(M=741 \mathrm{~ms}, S D=230 \mathrm{~ms}), t(29)=$ 9.03, $p<.001, d_{z}=1$.63.Participants seemed to group their responses: they strategically postponed Task 1 at long SOA to retrieve the stimulus sequence of Task 2, which in turn led to faster Task 2 processing.

Experiment 1: RTs of the two-choice task. A two-factorial ANOVA with block type and SOA (200 ms vs. $500 \mathrm{~ms}$ ) was performed to examine whether stimulus sequence and timing sequence affected the random task (presented first). There was a main effect of block type, $F(1.32,35.63)=38.89, p<$ $.001, \eta_{p}{ }^{2}=.59$. Further contrast analyses indicated quicker responses in the random SOA sequence stimuli test block $(M=707 \mathrm{~ms}, S D=147 \mathrm{~ms})$ than in the random SOA random stimuli test block $(M=$ $739 \mathrm{~ms}, S D=185 \mathrm{~ms}), F(1,27)=45.20, p<.001, \eta_{p}{ }^{2}=.63$, and in sequence SOA random stimuli test block $(M=732 \mathrm{~ms}, S D=162 \mathrm{~ms}), F(1,27)=17.32, p<.001, \eta_{p}{ }^{2}=.39$. No difference was revealed between random SOA random stimuli test block and sequence SOA random stimuli test block ( $p=$ .75). The main effect of SOA, $F(1,27)=26.12, p<.001, \eta_{p}{ }^{2}=.49$, suggested that RTs of the twochoice task were shorter in the $200 \mathrm{~ms}$ SOA condition $(M=659 \mathrm{~ms}, S D=182 \mathrm{~ms})$ than in the $500 \mathrm{~ms}$ SOA condition $(M=793 \mathrm{~ms}, S D=158 \mathrm{~ms})$. It might suggest SOA influenced which task was responded to first. We found also an interaction effect, block type $\times \operatorname{SOA}, F(2,54)=12.21, p<.001$, $\eta_{p}{ }^{2}=.31$. It indicated that RT differences of two-choice task between short and long SOA was larger when there was the stimulus sequence in the SRTT. The RT in Task 1 also benefitted from the sequence knowledge in Task 2.

Experiment 2: RTs of the two-choice task. In the two-choice task, we obtained a main effect of timing sequence, $F(1,29)=6.32, p=.018, \eta_{p}{ }^{2}=.18$. The main effect of SOA, $F(1,29)=76.85, p<$ $.001, \eta_{p}{ }^{2}=.73$, suggested the RTs of the two-choice task were shorter in $200 \mathrm{~ms}$ SOA condition $(M=$ $696 \mathrm{~ms}, S D=192 \mathrm{~ms})$ than in $500 \mathrm{~ms}$ SOA condition $(M=827 \mathrm{~ms}, S D=171 \mathrm{~ms})$. There was no main effect of stimulus sequence, $F(1,29)=3.60, p=.068, \eta_{p}{ }^{2}=.11$. Again, there was no interaction: Stimulus sequence $\times$ timing sequence, stimulus sequence $\times$ SOA, timing sequence $\times$ SOA, and stimulus sequence $\times$ timing sequence $\times \mathrm{SOA}, F s<1$. It indicated that disrupting the stimulus sequence, the timing sequence and SOA did not influence the behaviour on the two-choice task. 
PREDICTABLE STIMULUS AND TIMING IN DUAL-TASKING

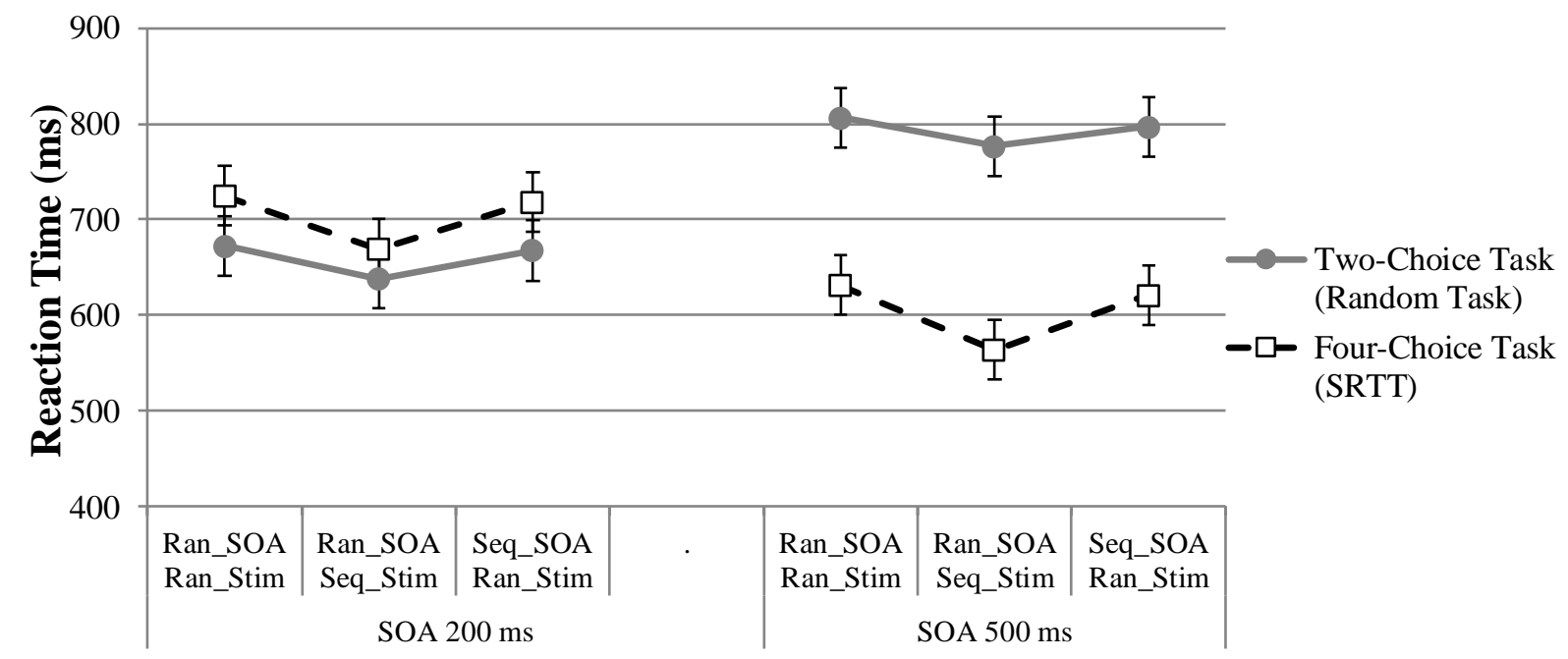

Figure A1. Experiment 1 excluding SRTT prior to two-choice task plotted with 95\% within subjects confidence intervals based on the error variance of block type (Masson \& Loftus, 2003).

Experiment 1: RTs of the SRTT. A two-factorial repeated measure ANOVA with block type and SOA ( $200 \mathrm{~ms}$ vs. $500 \mathrm{~ms}$ ) was performed to examine learning of the stimulus-response sequence. The main effect of block type, $F(1.45,39.15)=37.58, p<.001, \eta_{p}{ }^{2}=.58$, suggested shorter RTs in the condition involving a repeating stimulus sequence than other conditions. Contrast analyses showed that the RTs in the random SOA sequence stimuli test block $(M=616 \mathrm{~ms}, S D=180 \mathrm{~ms})$ were shorter than in the random SOA random stimuli test block $(M=678 \mathrm{~ms}, S D=183 \mathrm{~ms}, F(1,27)=5.28, p=$ $.03, \eta_{p}{ }^{2}=.16$, and the sequence SOA random stimuli test block $(M=670 \mathrm{~ms}, S D=174 \mathrm{~ms}, F(1,27)=$ $50.15, p<.001, \eta_{p}{ }^{2}=.65$. Thus, stimulus-response sequence knowledge enhanced performance.

The main effect of SOA, $F(1,27)=15.35, p=.001, \eta_{p}{ }^{2}=.36$, suggested the responses were shorter with long SOA ( $M=605 \mathrm{~ms}, S D=160 \mathrm{~ms})$ than short SOA $(M=704 \mathrm{~ms}, S D=204 \mathrm{~ms})$. The interaction of block type $\times \operatorname{SOA}, F(2,54)=12.95, p<.001, \eta_{p}{ }^{2}=.32$, indicated that the RT differences between short and long SOA was especially large when there was a repeating stimulus sequence. Presumably, stimulus sequence knowledge could be accessed and/or used better at long SOA.

Experiment 2: RTs of the SRTT. The impact of stimulus sequence (fixed sequence of stimuli and responses in the four-choice task vs. random sequence), timing sequence (fixed timing sequence vs. random timing sequence), and SOA ( $200 \mathrm{~ms}$ vs. $500 \mathrm{~ms}$ ) was tested in a $2 \times 2 \times 2 \mathrm{design}$. The ANOVA showed a main effect of stimulus sequence, $F(1,29)=28.64, p<.001, \eta_{p}{ }^{2}=.50$, suggesting that RTs in conditions that involved sequence stimulus conditions were shorter than in conditions that involved random stimulus. The main effect of timing sequence, $F(1,29)=5.44, p=.027, \eta_{p}{ }^{2}=.16$, indicated RTs in conditions involving a fixed timing sequence were shorter than in conditions involving random timing. The replicated main effect of SOA, $F(1,29)=105.68, p<.001, \eta_{p}{ }^{2}=.79$ suggested the responses were shorter with long SOA $(M=622 \mathrm{~ms}, S D=199 \mathrm{~ms})$ than short SOA $(M=$ $742 \mathrm{~ms}, S D=242 \mathrm{~ms}$ ). There was no interaction: Stimulus sequence $\times$ timing sequence, stimulus sequence $\times \mathrm{SOA}$, timing sequence $\times \mathrm{SOA}$, and stimulus sequence $\times$ timing sequence $\times \mathrm{SOA}, F s<1$. The results suggest that both the stimulus and timing sequence knowledge could be used independently of one another. 
PREDICTABLE STIMULUS AND TIMING IN DUAL-TASKING



Figure A2. Experiment 2 excluding SRTT prior to two-choice task plotted with 95\% within subjects confidence intervals based on the error variance of timing sequence $\times$ stimulus sequence (Masson $\&$ Loftus, 2003).

\section{Quintile analysis for Experiment 2}

The fastest two-choice trials had the shortest SRTT RTs. Furthermore, effects of sequence knowledge were present in the SRTT RTs of the trials with the fastest two-choice task responses.

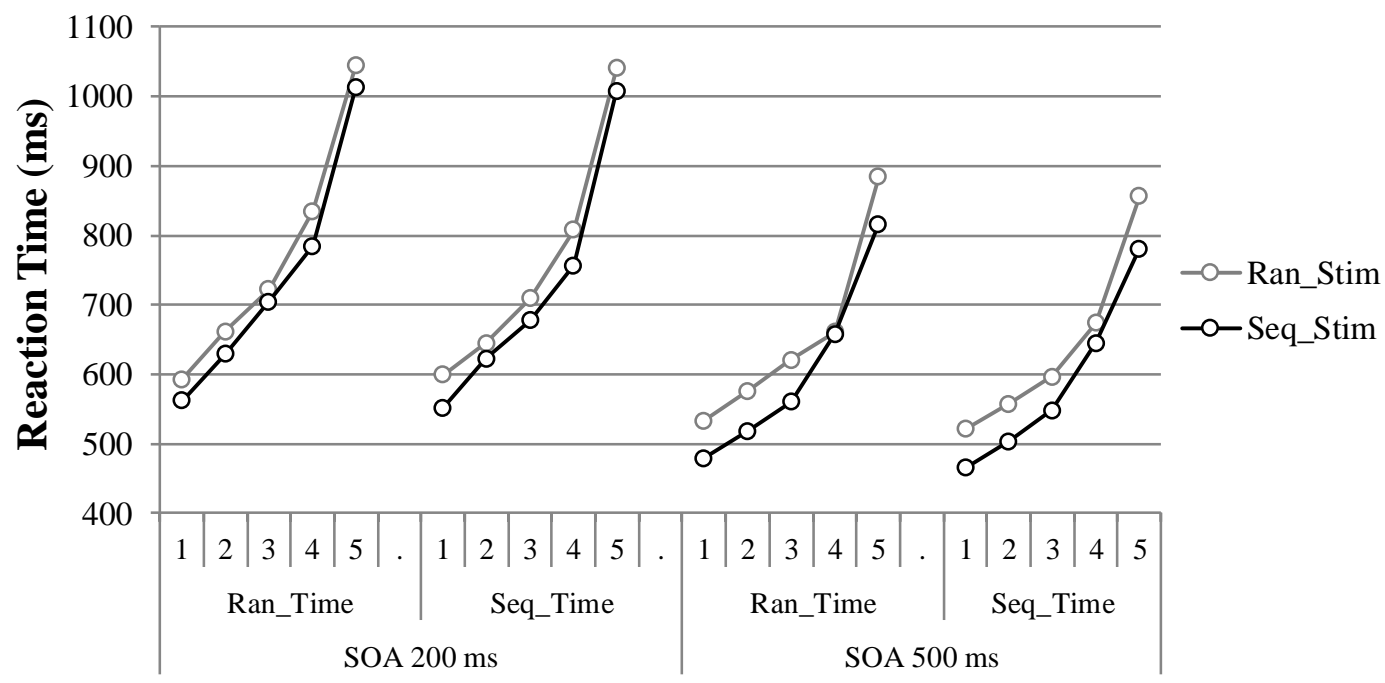

Figure A3. Quintile analysis of test phase data of Experiment 2. Quintiles were computed based on the two-choice task RT per participant, SOA, timing sequence and position sequence. 